\title{
Granitóides proterozóicos como marcadores da evolução geotectônica da região nordeste do Pará, Brasil
}

\author{
Edney Smith de Moraes Palheta ${ }^{1}$, Francisco de Assis Matos de Abreu ${ }^{2}$ \& \\ Candido Augusto Veloso Moura ${ }^{3}$
}

\begin{abstract}
Resumo Na região do Gurupi, nordeste do Pará, Brasil, afloram corpos granitóides em janelas erosivas das coberturas fanerozóicas. Eles representam marcadores importantes da evolução geotectônica da área e neste trabalho são investigados a partir de estudos isotópicos Sm-Nd e datações ${ }^{207} \mathrm{~Pb} /{ }^{206} \mathrm{~Pb}$ em monocristais de zircão. A maioria dos corpos tem gênese relacionada aos processos geológicos que formaram grande parte desse segmento crustal, onde se insere o Cráton São Luis. Tais processos remontam a um ambiente de interação entre arcos de ilhas e núcleos arqueanos, durante o Paleoproterozóico $(2,15-2,07 \mathrm{Ga})$. Um corpo granitóide, de idade eo-cambriana, $(549 \pm 4 \mathrm{Ma})$ foi formado durante a reativação tectônica que retrabalhou a borda sudoeste do cráton e que gerou o Cinturão de Cisalhamento Gurupi.
\end{abstract}

Palavras-chave: granitóides, Paleoproterozóico, Cráton São Luis.

\begin{abstract}
Proterozoic granitoids as indicators of the tectonic evolution of northeastern Pará, Brazil. Granitoids cropping out inside Phanerozoic sedimentary cover in northeast Pará, Brazil (Gurupi region), records the geotectonic evolution of this region. ${ }^{207} \mathrm{~Pb} /{ }^{206} \mathrm{~Pb}$ single zircon evaporation ages were obtained for different granitoid bodies of the region, besides Sm-Nd isotopic studies. Almost all the plutons are genetically related with regional geological processes operative during this crustal segment formation, which includes the São Luís Craton. Such processes are associated with amalgamation of island arcs and Archean nuclei during the Palaeoproterozoic (2.15 to 2,07 Ga). The reworking of the southwestern margin of the São Luís Craton at the end of the Neoproterozoic formed the Gurupi Belt and is recorded by the occurrence of a granitic pluton of $549 \pm 4 \mathrm{Ma}$.
\end{abstract}

Keywords: Granitoids, Palaeoproterozoic, São Luís Craton.

INTRODUÇÃ̃O Na porção nordeste do Estado do Pará, região do baixo rio Gurupi, no norte do Brasil, expõem-se rochas pré-cambrianas em janelas erosivas, em meio às coberturas fanerozóicas. Na região encontram-se duas unidades geotectônicas: o Cráton São Luís (Almeida et al. 1968) e o Cinturão de Cisalhamento Gurupi (Costa et al. 1988), que são separadas pela Zona de Cisalhamento Tentugal-ZCT (NW-SE).

Nas áreas a norte-nordeste do Cráton São Luiz ocorrem rochas paleoproterozóicas com idades em torno de 2,0 Ga (Hurley et al. 1967, Wanderley Filho 1980, Lowell 1985, Souza inédito, Klein 1998). A sudoeste da Zona de Cisalhamento Tentugal ocorre rochas neoproterozóicas, datadas entre 518-723 Ma (João Jorge apud Villas 1982, Hurley et al. 1967 e Villas 1982).

O Cráton São Luís apresenta semelhanças litoestratigráficas, estruturais, geocronológicas e geofísicas com o Cráton Oeste Africano, sobretudo com as unidades geológicas encontradas em Gana e Costa do Marfim (Almeida et al. 1968, Abreu \& Lesquer 1985). Essas analogias sustentam a interpretação de que o Cráton São Luís representa um fragmento do Cráton Oeste Africano na América do Sul, quando da ruptura do Gondwana (Hur- ley et al. 1967, Abreu 1990). Abreu \& Lesquer (1985), através de estudos gravimétricos, notaram que a estruturação regional das unidades litoestratigráficas, da porção dita cratônica, tem orientação NE-SW, em contraposição àquela da área meridional que possui direções NW-SE.

O Cinturão de Cisalhamento Gurupi, teria evoluído num modelo com dois estágios. O primeiro estaria relacionado a um tectonismo compressivo oblíquo que gerou cavalgamentos (sistema imbricado) com movimentação de massa de SW para NE, formando rampas laterais. Esse quadro cinemático foi posteriormente substituído por outro no qual predominaram transcorrências sinistrais com direção NW-SE (Pastana 1995, Borges et al. 1996, Costa \& Hasui 1997, Costa 2000).

Datações geocronológicas mais recentes revelaram idades de 2,05 Ga (C. A. V. Moura inédito) e 2,4 Ga (Oliveira inédito) para granitóides alojados no Cinturão de Cisalhamento Gurupi. Estas idades foram obtidas, respectivamente, pelos métodos $\mathrm{Rb}-\mathrm{Sr}$ em rocha total e evaporação de $\mathrm{Pb}$ em monocristais de zircão. Em função do posicionamento dos corpos datados, estes dados estão em contraposição à interpretação da existência de dois domínios geocronológicos distintos, anteriormente citados.

1 - CPRM - Serviço Geológico do Brasil - REFO, Fortaleza (CE), Brasil. E-mail: edney@fo.cprm.gov.br

2 - Universidade Federal do Pará, Instituto de Geociências, Faculdade de Geologia, Belém (PA), Brasil. E-mail: famatos@ufpa.br

3 - Universidade Federal do Pará, Instituto de Geociências, Faculdade de Geologia, Laboratório de Geologia Isotópica - Pará-Iso, Belém

(PA), Brasil. E-mail: candido@ufpa.br 
Apresenta-se neste trabalho novos dados geocronológicos, obtidos pelo método de evaporação $\mathrm{Pb}$ em monocristais de zircão ( $\mathrm{Pb}-\mathrm{Pb}$ em zircão), em rochas granitóides situadas nas duas unidades geotectônicas anteriormente mencionadas, os quais sugerem que rochas paleoproterozóicas estão presentes no domínio do Cinturão de Cisalhamento Gurupi. Além disso, são também apresentadas idades modelo Sm-Nd $\left(\mathrm{T}_{\mathrm{DM}}\right)$ dos granitóides datados que reforçam essa interpretação. Em função das características petrográficas, das feições estruturais impressas e dos dados isotópicos obtidos, estes granitóides são aqui utilizados como marcadores da evolução geotectônica desse segmento crustal no Proterozóico.

GEOLOGIA REGIONAL As unidades litoestratigráficas reconhecidas no Cráton São Luís e no Cinturão de Cisalhamento Gurupi são apresentadas na figura 1.

No cráton predominam rochas de composição tonalítica, trondhjemítica e granodiorítica que foram agrupadas na Suíte Tromaí. São rochas de afinidade cálcio-alcalina do tipo-I (Pastana 1995), localmente deformadas e com marcantes efeitos de alteração hidrotermal. Datações pelo método $\mathrm{Pb}-\mathrm{Pb}$ em zircão indicam idades entre 2,15-2,16 Ga para este magmatismo (Klein \& Moura 2001). Associadas as rochas da Suíte Tromaí, ocorrem rochas metavulcanossedimentares, reunidas no Grupo Aurizona, que são representadas por xistos, filitos, quartzitos, metadacitos, metapiroclásticas, metacherts, metaultramáficas e metamáficas, metamorfisados no fácies xisto-verde e, mais raramente, fácies anfibolito. Resultados $\mathrm{Pb}-\mathrm{Pb}$ em zircão de 2,24 $\mathrm{Ga} \mathrm{em}$ rochas metapiroclásticas atestam a idade paleoprotero-

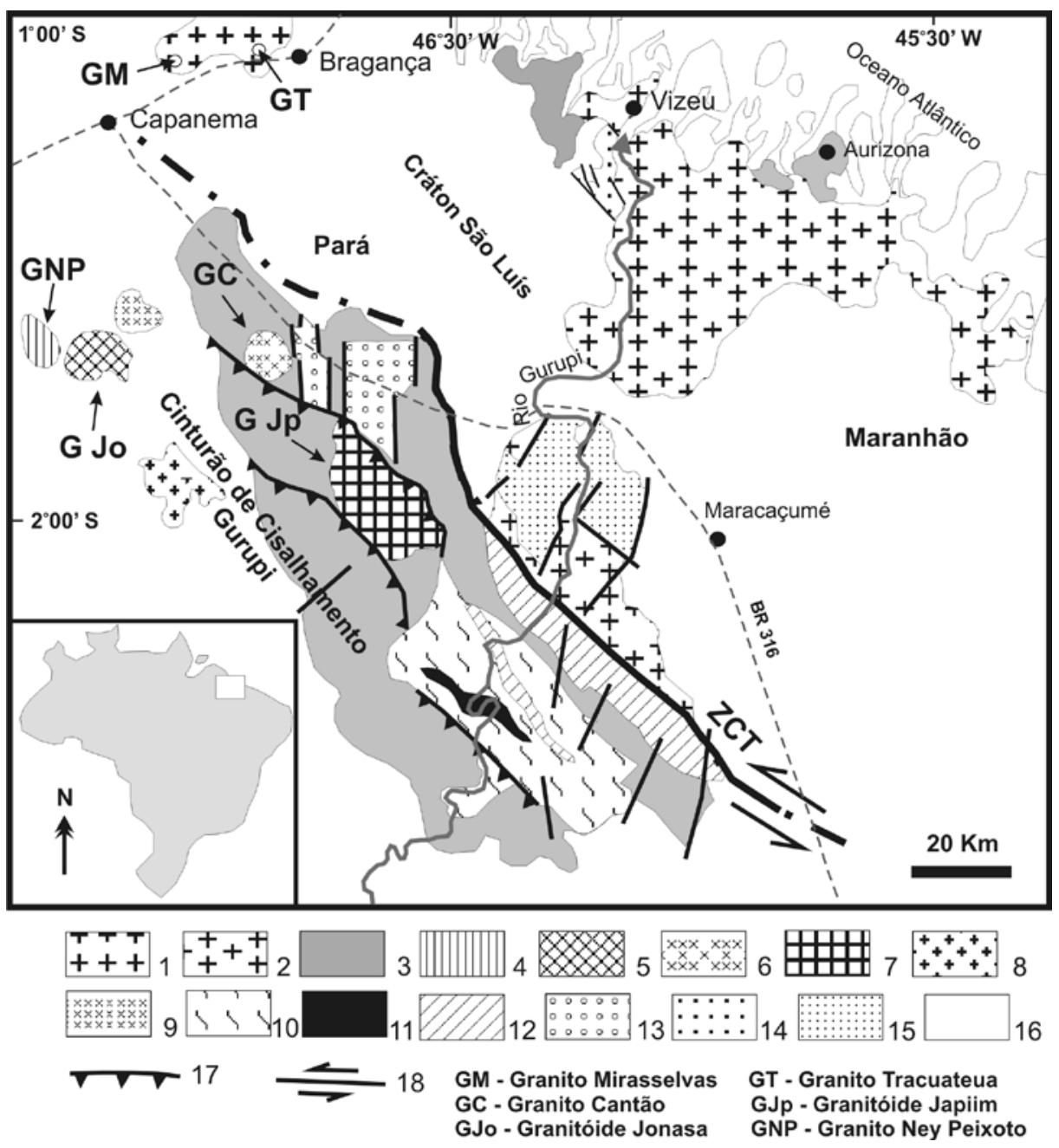

Figura 1 - Distribuição espacial das unidades litoestratigráficas da região do Gurupi (nordeste do Pará e noroeste do Maranhão). Compilado e modificado de Almeida (2000), Costa (2000) e Pastana (1995). 1- Suite Tracuateua, 2- Suite Tromai, 3- Grupo Gurupi, 4- Granito Ney Peixoto, 5- Granito Jonasa, 6- Granito Cantão, 7- Granito Japiim, 8- Gnaisse Boca Nova, 9- Granitóide Ourém, 10Complexo Maracaçumé, 11- Granito Maria Suprema, 12- Suite Tromai Retrabalhada, 13- Formação Piriá, 14- Formação Vizeu, 15- Formação Igarapé de Areia, 16- Coberturas fenerozóicas, 17-Cavalgamento, 18-Transcorrência sinistral. 
zóica destes conjuntos (Klein \& Moura 2001). Ainda na região cratônica, os corpos graníticos de Mirasselvas e Tracuateua, caracterizados como fortemente peraluminosos e interpretados geoquimicamente como do tipo S (Lowel 1985), foram reunidos na Suíte Tracuateua (Costa 2000). Datações Rb-Sr e K-Ar para essas rochas revelaram idades em torno de 2,0 Ga (Hurley et al. 1967, Wanderley Filho 1980). Completam esse quadro litoestratigráfico as coberturas cratônicas reunidas nas formações Vizeu e Igarapé de Areia que são representadas por metarenitos arcoseanos com lentes de conglomerados.

No Cinturão de Cisalhamento Gurupi predominam rochas vulcanossedimentares metamorfisadas em condições que variam de xisto-verde a anfibolito baixo, representadas por ardósias, filitos e diversos xistos reunidas no Grupo Gurupi. Costa (2000) individualizaram, no mapeamento da Folha Castanhal, os mesmos litotipos, aos quais denominaram formações Peritoró, Jeritequara e Vila Cristal, atribuindo-as, também, ao Grupo Gurupi. Datações geocronológicas em rochas do Cinturão de Cisalhamento Gurupi pelos métodos $\mathrm{Rb}-\mathrm{Sr}$ e K-Ar em minerais revelaram idades de $1.096 \pm 104$, $580 \pm 91,746 \pm 192$ (Cordani et al. 1984). Ainda no domínio do Cinturão de Cisalhamento Gurupi ocorrem gnaisses de composição tonalítica e granodiorítica além de migmatitos, os quais foram agrupados no Complexo Maracaçumé. Gorayeb et al. (1999) levantaram a possibilidade do Complexo Maracaçumé, encerrar litotipos, intensamente deformados, da Suíte Tromaí, em razão da semelhança das rochas contidas nessas duas unidades. Alojados nas rochas metavulcanossedimentares do Cinturão de Cisalhamento Gurupi ocorrem ainda diversos granitóides denominados de Cantão, Jonasa, Japiim, Ourém e Ney Peixoto. Esse conjunto de granitóides tem sido designado como Suíte Granitóide Brasiliana (Hasui et al. 1984) em função da idade Rb-Sr em rocha total de 544 Ma obtida para o Granito Ney Peixoto (Villas 1982). No entanto, a idade de $2.051 \pm$ 165 Ma foi obtida para o Granito Cantão pelo método $\mathrm{Rb}-\mathrm{Sr}$ em rocha total (C. A. V. Moura, inédito) e idades $\mathrm{Pb}-\mathrm{Pb}$ em zircão ao redor de 2,4 Ga foram obtidas para o Granito Jonasa (Oliveira inédito).

No Cinturão de Cisalhamento Gurupi encontram-se, ainda, o Gnaisse Boca Nova com idade $\mathrm{Rb}-\mathrm{Sr}$ em rocha total de $723 \pm 30 \mathrm{Ma}$ (Villas 1982). Recobrindo as rochas desse cinturão ocorrem arcóseos, sub-arcóseos e argilitos da Formação Piriá, tida como do Eocambriano (Costa 2000). Os dados geológicos e geocronológicos existentes apontam para uma evolução crustal, que se iniciou no Paleoproterozóico, durante o Evento Transamazônico (domínio cratônico), prosseguiu e finalizou-se no Neoproterozóico/Eocambriano (domínio móvel), durante o Evento Brasiliano. A tabela 1 sintetiza os resultados obtidos através dos métodos $\mathrm{Rb}-\mathrm{Sr}, \mathrm{K}-\mathrm{Ar}$ e $\mathrm{Pb}-\mathrm{Pb}$ em zircão na região abordada pelo presente estudo.

GEOLOGIA DOS GRANITÓIDES O mapa geológico da região do Gurupi (Fig. 1) apresenta os corpos graníticos estudados (Cantão, Japiim, Jonasa, Ney Peixoto, Tracuateua e Mirasselvas) que foram descri- tos por Palheta (2001). Os dois últimos estão inseridos na área considerada cratônica e os demais no Cinturão de Cisalhamento Gurupi. As relações de contato entre esses corpos e as suas encaixantes são desconhecidas, sendo ocultadas pelas coberturas fanerozóicas, exceto as do Corpo Cantão, o qual é intrusivo nas supracrustais do Grupo Gurupi (Borges et al. 1988).

Granito Tracuateua (GT) Sua melhor exposição encontra-se nos arredores da cidade de Tracuateua. Este corpo possui rochas de colorações que variam de róseo, cinza rosado a cinza esbranquiçado, possuindo uma textura isotrópica, fanerítica, hololeucocrática a leucocrática, granulação variando de média a grossa. São constituídas por quartzo $(36,8-31,8 \%)$, microclina $(35,6-19,6 \%)$, albita-oligoclásio (28,3-18,5\%), muscovita (16,6-6,4\%) e biotita $(5,2-1,0 \%)$. Como acessórios ocorrem zircão, apatita e minerais opacos. Apresenta variações, geralmente, de muscovita-biotita monzogranito a sienogranito. Xenólitos de biotita-xisto, de dimensões centimétrica e raramente métrica, são encontrados.

Granito Mirasselvas (GM) Expõe-se na pedreira Mirasselvas, hoje desativada, nas adjacências do rio Quatipuru, no povoado de Pedreira, próximo à vila de Mirasselvas. Este corpo apresenta colorações que variam de cinza, cinza escuro a cinza esbranquiçado, textura fanerítica, hololeucocrática a leucocrática, granulação média a grossa, algumas vezes fina. Os minerais essenciais presentes são quartzo $(37,1-27,8 \%)$, microclina $(32,4-18,9 \%)$, albita-oligoclásio $(29,7-22,3 \%)$, biotita $(13,7-5,3 \%)$ e muscovita $(10,9-2,7 \%)$. Como acessórios ocorrem apatita, zircão e minerais opacos. A rocha é classificada como biotita-muscovita monzogranito.

Ocorrem associados veios pegmatóides, de largura centimétrica, com cristais de muscovita de até $3 \mathrm{~cm}$, como também cristais de granada. São encontrados aplitos e pequenas injeções quartzo-feldspáticas, além de faixas decimétricas a métricas, onde existe concentração de deformação, demonstrando que esse processo dinâmico manifesta-se no corpo de forma heterogênea. Nessas porções ocorrem foliações miloníticas orientadas na direção $277^{\circ}-295^{\circ} \mathrm{Az}$ com mergulhos médios a relativamente altos, geralmente, com valores entre $48^{\circ}-68^{\circ}$ para SSW. A lineação de estiramento mineral (quartzo e feldspatos) possui um caimento ao redor de $5^{\circ}-14^{\circ}$ no sentido variável entre $95^{\circ}-120^{\circ} \mathrm{Az}$. A relação espacial entre essas estruturas indica um ângulo baixo para o rake, indicando a predominância de movimentação direcional. Além da foliação milonítica, o corpo apresenta discreta foliação $\mathrm{S} / \mathrm{C}$ dextral e foliação caracterizada pela orientação de minerais micáceos na direção ESE-WNW com caimento para SW.

Granito Cantão (GC) Localiza-se a sudoeste da cidade de Santa Luzia do Pará, na vila Cantão. Apresenta colorações que variam de cinza a cinza esbranquiçado, textura isotrópica, fanerítica, leucocrática, granulação grossa a muito grossa, raramente fina a média. Destacam-se fenocristais centimétricos de álcali-feldspato (euédricos 
Tabela 1(a e b) - Síntese geocronológica da região do Gurupi.

Domínio Cratônico (Cráton São Luís)

\begin{tabular}{|c|c|c|c|c|}
\hline Unidade & Litotipo & Método & Idade (Ma) & Referências \\
\hline Suíte Tromaí & $\begin{array}{l}\text { Tonalito } \\
\text { Microtonalito } \\
\text { Trondjehmito } \\
\text { Monzogranito } \\
\text { Tonalito }\end{array}$ & $\begin{array}{l}\mathrm{Pb} / \mathrm{Pb}^{1} \\
\mathrm{~Pb} / \mathrm{Pb}^{1} \\
\mathrm{~Pb} / \mathrm{Pb}^{1} \\
\mathrm{~Pb} / \mathrm{Pb}^{1} \\
\mathrm{~Pb} / \mathrm{Pb}^{1}\end{array}$ & $\begin{array}{l}2.132 \pm 18 \\
1.982 \pm 6 \\
2.165 \pm 2 \\
2.163 \pm 3 \\
2.149 \pm 5\end{array}$ & $\begin{array}{l}\text { Sousa (inédito) } \\
\text { Klein (1998) } \\
\text { Klein \& Moura (2001) } \\
\text { Klein \& Moura (2001) } \\
\text { Klein \& Moura (2001) }\end{array}$ \\
\hline Suíte Tracuateua & $\begin{array}{l}\text { Granitóide } \\
\text { Granito } \\
\text { Granito } \\
\text { Granito }\end{array}$ & $\begin{array}{l}\mathrm{Rb} / \mathrm{Sr}^{2} \\
\mathrm{~K} / \mathrm{Ar}^{2} \\
\mathrm{~K} / \mathrm{Ar}^{3} \\
\mathrm{~K} / \mathrm{Ar}^{2} \\
\mathrm{Rb} / \mathrm{Sr}^{\mathrm{RT}}\end{array}$ & $\begin{array}{l}2.070 \\
1.933 \\
1.906 \pm 54 \\
2.056 \pm 41 \\
2.047 \pm 140\end{array}$ & $\begin{array}{l}\text { Hurley et al. (1967) } \\
\text { Hurley et al. (1967) } \\
\text { Wanderley Filho (inédito) apud Abreu (1990) } \\
\text { Wanderley Filho (inédito) apud Abreu (1990) } \\
\text { Wanderley Filho } 1980\end{array}$ \\
\hline Grupo Gurupi & $\begin{array}{l}\text { Filito } \\
\text { Ardósia } \\
\text { Metapiroclástica }\end{array}$ & $\begin{array}{l}\mathrm{Rb} / \mathrm{Sr}^{\mathrm{RT}} \\
\mathrm{Rb} / \mathrm{Sr}^{\mathrm{RT}} \\
\mathrm{Pb} / \mathrm{Pb}^{1}\end{array}$ & $\begin{array}{l}2.054 \pm 64 \\
1.820 \\
2.240 \pm 5\end{array}$ & $\begin{array}{l}\text { Amaral (1974) apud Abreu (1990) } \\
\text { Cordani et al. }(1984) \\
\text { Klein \& Moura (2001) }\end{array}$ \\
\hline
\end{tabular}

Domínio Móvel (Cinturão Gurupi)

\begin{tabular}{|c|c|c|c|c|}
\hline Unidade & Litotipo & Método & Idade (Ma) & Referências \\
\hline Granito Ney Peixoto & $\begin{array}{l}\text { Granito } \\
\text { Granito } \\
\text { Granito }\end{array}$ & $\begin{array}{l}\mathrm{Rb} / \mathrm{Sr}^{\mathrm{RT}} \\
\mathrm{Rb} / \mathrm{Sr} r^{\mathrm{RT}} \\
\mathrm{Rb} / \mathrm{Sr}^{\mathrm{RT}}\end{array}$ & $\begin{array}{l}544 \pm 22 \\
553 \\
559\end{array}$ & $\begin{array}{l}\text { Villas (1982) } \\
\text { Hurley et al. (1967) } \\
\text { Hurley et al. (1967) }\end{array}$ \\
\hline $\begin{array}{l}\text { Suíte Alcalina Boca } \\
\text { Nova }\end{array}$ & Gnaisse & $\begin{array}{l}\mathrm{Rb} / \mathrm{Sr}^{\mathrm{RT}} \\
\mathrm{K} / \mathrm{Ar}^{3}\end{array}$ & $\begin{array}{l}723 \pm 30 \\
518 \pm 10\end{array}$ & $\begin{array}{l}\text { Villas (1982) } \\
\text { Jorge João (inédito) apud Villas (1982) }\end{array}$ \\
\hline Granito Cantão & Granito & $\mathrm{Rb} / \mathrm{Sr}^{\mathrm{RT}}$ & $2.051 \pm 165$ & C. A. V. Moura (inédito) \\
\hline Granitóide Jonasa & Granitóide & $\mathrm{Pb} / \mathrm{Pb}^{1}$ & $2.416 \pm 31$ & Oliveira (inédito) \\
\hline Grupo Gurupi & $\begin{array}{l}\text { Filito } \\
\text { Metaconglomerado } \\
\text { Metaconglomerado } \\
\text { Matriz de } \\
\text { metaconglomerado }\end{array}$ & $\begin{array}{l}\mathrm{Rb} / \mathrm{Sr}^{\mathrm{RT}} \\
\mathrm{Rb} / \mathrm{Sr}^{\mathrm{RT}} \\
\mathrm{Rb} / \mathrm{Sr}^{\mathrm{RT}} \\
\mathrm{Rb} / \mathrm{Sr}^{\mathrm{RT}}\end{array}$ & $\begin{array}{l}520 \\
1.096 \pm 104 \\
580 \pm 91 \\
746 \pm 192\end{array}$ & $\begin{array}{l}\text { Cordani et al. (1984) } \\
\text { Cordani et al. }(1984) \\
\text { Cordani et al. }(1984) \\
\text { Cordani et al. }(1984)\end{array}$ \\
\hline
\end{tabular}

1- Zircão, 2-Muscovita, 3- Biotita, RT- rocha total.

a subédricos). $\mathrm{O}$ corpo encontra-se seccionado por veios quartzo-feldspáticos, de largura centimétrica. É constituído por oligoclásio $(42,3-33,1 \%)$, microclina $(34,7-$ $24,0 \%)$, quartzo $(23,5-18,9 \%)$ e biotita $(11,8-6,2 \%)$. Como acessórios estão presentes apatita, zircão, titanita e pistacita. Sua composição modal indica tratar-se de biotita monzogranito. Estão embutidos enclaves escuros, ricos em biotita, de formas tabulares arredondadas, ovaladas e elípticas, alcançando até $45 \mathrm{~cm}$, segundo o seu eixo maior. Este corpo é considerado intrusivo na seqüência metassedimentar do Grupo Gurupi (Borges et al. 1988).

Granitóide Japiim (GJp) É um corpo de dimensões batolíticas situado no município de Vizeu. Nele são encontrados veios de quartzo de largura centimétrica, em várias direções. Apresenta duas variações fa- ciológicas principais:

FÁCIES MONZOGRANÍTICA A SIENOGRANÍTI$C A$ Esta fácies é a mais representativa do batólito, aflorando nos arredores da vila Japiim. As rochas apresentam colorações esbranquiçada, cinza esbranquiçada a cinza escuro, textura fanerítica, hololeucocrática a leucocrática e granulação grossa, individualizando duas texturas: uma isotrópica e outra milonítica que é marcada pelo traço anastomosado de micas, envolvendo cristais de feldspatos e quartzo. A porção isotrópica tem como minerais essenciais, quartzo $(35,4-32,5 \%)$, microclina (29,3-26,6\%), albita-oligoclásio (25,2-21,7\%), biotita $(13,6-2,7 \%)$, muscovita $(9,6-4,2 \%)$. Como acessórios ocorrem apatita, zircão e pistacita. Esta fácies apresenta variações de muscovita monzogranito, bioti- 
ta-muscovita monzogranito, muscovita-biotita monzogranito e muscovita-biotita sienogranito. As feições deformacionais estão impressas em um leucosienogranito. Ao microscópio, os minerais essenciais são quartzo $(39,2-33,2 \%)$, microclina $(38,1-32,1 \%)$, plagioclásio (30,6-19,1\%) e muscovita $(4,1-2,1 \%)$, e como acessório zircão. Esse litotipo apresenta cristais porfiríticos (feldspatos) microfraturados, plagioclásio com maclas distorcidas, quartzo com feições de recovery e em forma de subgrãos, e micas em feições fish. Diversos fragmentos de microclina, plagioclásio e quartzo resultam da cominuição de cristais e foram gerados a partir do desenvolvimento de uma deformação rúptil-dúctil. Este processo gerou na rocha transformações que se situam entre os estágios de protomilonito a milonito.

FÁCIES GRANODIORÍTICA Ocorre nos arredores da vila Timbozal. Compreende rochas de coloração cinza com tons rosados, textura isotrópica, fanerítica, leucocrática, granulação grossa a muito grossa. Este litotipo apresenta fenocristais euédricos a subédricos, de álcali-feldspato, com dimensões centimétricas. Mineralogicamente são encontrados quartzo $(43,90 \%)$, oligoclásio-andesina $(39,50 \%)$, microclina $(8,90 \%)$, biotita $(6,70 \%)$. Como acessórios ocorrem titanita, apatita e zircão. A composição modal indica tratar-se de biotita granodiorito porfirítico. O Granitóide Japiim, em suas faixas deformadas, tem como estrutura planar principal uma foliação milonítica, sendo observada também, uma sutil foliação $\mathrm{S} / \mathrm{C}$ sinistral. A foliação milonítica orienta-se, principalmente, na direção $125^{\circ}-155^{\circ} \mathrm{Az}$, com mergulhos entre $25^{\circ}-55^{\circ}$ para NE e ENE. A lineação é caracterizada por cristais de quartzo estirados, com mergulhos, geralmente, entre $20^{\circ}-33^{\circ}$ para $70^{\circ}-$ $95^{\circ} \mathrm{Az}$. A relação espacial entre a foliação e a lineação indica um valor médio para o rake.

Granitóide Jonasa (GJo) Aflora na Fazenda Cachoeira, em uma antiga pedreira, hoje um balneário. Este corpo apresenta coloração cinza esbranquiçada, é fanerítico, leucocrático e tem granulação variando de fina a grossa. Predomina incipiente bandamento composicional, marcado por alternância de minerais máficos e félsicos. É composto por oligoclásio-andesina $(44,2-36,1 \%)$, quartzo $(31,8-21,7 \%)$, microclina $(19,2-$ $11,0 \%)$, biotita $(13,1-9,4 \%)$ e muscovita $(12,3-2,4 \%)$. Como minerais acessórios ocorrem zircão e titanita. Sua composição modal indica tratar-se de biotitamuscovita metagranodiorito. Estão presentes veios, de dimensões centimétricas a métricas, de composição granítica, corpos pegmatóides tabulares e sob a forma de bolsões, contendo berilo e granada, subconcordante e discordantemente à foliação. Segregações de sílica geraram cristais maiores e bolsões dentro do granitóide e estruturas de arrasto modificam a direção regional da foliação. Estruturalmente, o corpo destaca contornos entrelaçados das micas entre cristais de feldspato e quartzo, desenvolvendo uma foliação milonítica, com orientação entre $320^{\circ}-351^{\circ} \mathrm{Az}$, e mergulhos que variam de médio a alto, entre $25^{\circ}-80^{\circ}$ para WSW. A lineação de estiramento mineral (alongamento de cristais de quartzo) tem dois posicionamentos espaciais. $\mathrm{O}$ primeiro com mergulhos baixos entre $3^{\circ}-11^{\circ}$, no intervalo de $325^{\circ}-353^{\circ} \mathrm{Az}$. O segundo com ângulos de caimento entre $24^{\circ}-26^{\circ}$ e azimutes entre $263^{\circ}-267^{\circ}$. Estas relações espaciais indicam duas situações para o rake: uma de ângulo baixo (predominante) e uma segunda com ângulo de quase $90^{\circ}$.

Granito Ney Peixoto (GNP) Aflora, principalmente, na pedreira homônima, atualmente desativada. Possui coloração cinza a cinza esbranquiçada, textura fanerítica, leucocrática, granulação média a grossa. Consiste de quartzo $(33,9-23,3 \%)$, microclina $(30,2-24,5 \%)$, albitaoligoclásio (32,2-21,4\%), biotita $(15,1-10,7 \%)$ e muscovita $(9,2-6,1 \%)$. Como acessórios ocorrem apatita, zircão, epidoto e minerais opacos. Trata-se, assim, de biotitamuscovita monzogranito. Neste corpo, estão presentes veios quartzo-feldspáticos e pegmatóides centimétricos a métricos, concordantes, sub concordantes e discordantes. Apresenta uma incipiente foliação, dada pela disposição espacial de muscovita e biotita, que emprestam um caráter foliado a rocha. Esta foliação acompanha sub concordantemente o desenho de dobras fechadas, de movimentação geralmente sinistral. A foliação posiciona-se entre $310^{\circ}-344^{\circ} \mathrm{Az}$ com mergulhos entre $63^{\circ}-85^{\circ}$ para $\mathrm{SW}$. Não foram observadas estruturas lineares. Descontinuidades estão presentes na região, representadas por juntas nas direções principais NW-SE e N-S, e secundariamente NNW-SSE, WSW-ENE e W-E. As falhas são, sobretudo, orientadas segundo NW-SE e NNE-SSW, com menor incidência nas direções NNW-SSE e W-E.

\section{GEOCRONOLOGIA DOS GRANITÓIDES}

Métodos analíticos Os granitóides foram datadas pelo método de evaporação de $\mathrm{Pb}$ em monocristais de zircão ( $\mathrm{Pb}-\mathrm{Pb}$ em zircão), o qual determina a idade aparente do zircão com base na razão isotópica ${ }^{207} \mathrm{~Pb} /{ }^{206} \mathrm{~Pb}$ (Kober 1986, 1987). Adicionalmente foram também determinadas idades modelo Sm-Nd desses corpos.

Os cristais de zircão foram extraídos a partir de $30 \mathrm{~kg}$ de amostra de rocha sã. Após trituração e peneiramento das amostras, os cristais de zircão provenientes da fração granulométrica entre $0,125-0,250 \mathrm{~mm}$ foram separados com o uso do elutriador, do separador magnético Isodynamic Frantz e de líquidos pesados. Os cristais de zircão foram selecionados a partir da fração não magnética, obtidos no separador magnético com calibragem de $20^{\circ}$ de inclinação longitudinal, $0^{\circ}$ de inclinação lateral e corrente de 1,5 ampéres. A escolha dos cristais apropriados para a análise isotópica foi feita com o auxílio de uma lupa binocular e do microscópio petrográfico. As análises isotópicas foram realizadas no espectrômetro de massa Finnigam MAT 262, do Laboratório de Geologia Isotópica, da Universidade Federal do Pará (Pará-Iso). No procedimento adotado no ParáIso, o cristal de zircão é depositado em filamento de rênio em forma de canoa (filamento de evaporação) que é posicionado no carrossel do espectrômetro em frente à outro filamento de rênio (filamento de ionização). O filamento de evaporação é aquecido para evaporar 
os átomos de $\mathrm{Pb}$ do zircão, que se depositam no filamento de ionização (etapa de evaporação). Em seguida o filamento de evaporação é desligado e o filamento de ionização é aquecido para ionizar os átomos de $\mathrm{Pb}$ ali depositados, visando determinar a razão isotópica ${ }^{207} \mathrm{~Pb} /{ }^{206} \mathrm{~Pb}$ do cristal de zircão daquela etapa de evaporação. Em geral são realizadas três etapas de evaporação nas temperaturas de $1.450^{\circ} \mathrm{C}, 1.500^{\circ} \mathrm{C}, 1.550^{\circ} \mathrm{C}$. A aquisição dos dados é realizada por meio de um contador de íons e a intensidade no sinal de $\mathrm{Pb}$ é medida na ordem de massa 206, 207, 208, 206, 207 e 204, ao longo de 10 varreduras, definindo um bloco com 18 razões ${ }^{207} \mathrm{~Pb} /{ }^{206} \mathrm{~Pb}$. A média das razões ${ }^{207} \mathrm{~Pb} /{ }^{206} \mathrm{~Pb}$, de cada etapa de evaporação é determinada a partir de 5 blocos ou até quando o sinal de $\mathrm{Pb}$ for suficiente para análise. As razões ${ }^{207} \mathrm{~Pb} /{ }^{206} \mathrm{~Pb}$ adquiridas nas altas temperaturas são, normalmente, as utilizadas para o cálculo da idade aparente. A idade ${ }^{207} \mathrm{~Pb} /{ }^{206} \mathrm{~Pb}$ calculada é corrigida para $\mathrm{Pb}$ comum com base na razão ${ }^{204} \mathrm{~Pb} / 206 \mathrm{~Pb}$, sendo eliminados desse cálculo os blocos com razão ${ }^{204} \mathrm{~Pb} /{ }^{206} \mathrm{~Pb}$ superiores a 0,0004. A idade da rocha é determinada a partir da média ponderada das idades dos cristais analisados e os erros analíticos são apresentados com $2 \sigma$ de desvio padrão da média.

Para análise pelo método Sm-Nd, pesou-se cerca de 100mg de amostra pulverizada e, aproximadamente, $200 \mathrm{mg}$ de traçador misto $\left({ }^{149} \mathrm{Sm} /{ }^{150} \mathrm{Nd}\right)$. A abertura da amostra foi realizada com $\mathrm{HF}$ e $\mathrm{HNO}_{3}$ a $145^{\circ} \mathrm{C}$, usandose bombas Paar. A dissolução foi complementada com subseqüentes ataques de $\mathrm{HF}$ e $\mathrm{HCl}$, a $100^{\circ} \mathrm{C}$. $\mathrm{O} \mathrm{Sm} \mathrm{e} \mathrm{o}$ $\mathrm{Nd}$ foram separados por cromatografia de troca iônica em duas etapas. Primeiramente, separou-se os elementos terras raras (ETR), utilizando-se a resina catiônica $D O$ -
WEX 50WX-8. Em seguida o Sm e o Nd foram extraídos do conjunto (ETR) com resina aniônica DOWEX AG1-X4. As razões isotópicas foram medidas em um espectrômetro de massa da marca Finnigam MAT 262, do Pará-Iso. O Sm foi analisado em filamento simples de rênio, enquanto o Nd com arranjo de filamento tântalorênio (evaporação-ionização). As razões ${ }^{143} \mathrm{Nd} /{ }^{144} \mathrm{Nd}$ foram normalizadas para a razão de ${ }^{146} \mathrm{Nd} /{ }^{144} \mathrm{Nd}=0,7219$, e são fornecidas com erro de $2 \sigma$. O Nd padrão (La Jolla) medido durante o período de análise teve uma média de razão ${ }^{143} \mathrm{Nd} /{ }^{144} \mathrm{Nd}$ de $0,511829 \pm 8(2 \sigma)$. As idades modelo $\left(\mathrm{T}_{\mathrm{DM}}\right)$ foram calculadas com base na evolução isotópica do Nd de De Paolo (1988).

\section{Resultados}

$\mathrm{Pb}-\mathrm{Pb}$ EM ZIRCÃO O estudo geocronológico (Tab. 2) foi realizado em monzogranitos (Tracuateua, Mirasselvas, Cantão e Ney Peixoto) e granodioritos (Jonasa e Japiim).

Os cristais de zircão do GT são prismáticos, bipiramidais, alguns deles irregulares, translúcidos, às vezes incolores, de colorações amarelado, castanho claro e róseo. Raramente apresentam fraturas, inclusões ou sobrecrescimento, porém, ocorrem vários cristais metamíticos. Doze cristais foram analisados e apenas seis forneceram sinal de $\mathrm{Pb}$ suficiente para análise isotópica. Quatro cristais forneceram idades aparentes ${ }^{207} \mathrm{~Pb} /{ }^{206} \mathrm{~Pb}$ variando de $2.074 \pm 7$ a $2.087 \pm 7 \mathrm{Ma}$, definindo uma idade média de $2.080 \pm 2 \mathrm{Ma}$ (Tab. 2). Um zircão (TZ/11) apresentou uma idade de $2.107 \pm 3$ Ma que não se superpôs à idade média, tendo sido considerado como um cristal herdado.

Os zircões do GM têm formas prismáticas, bi-

Tabela 2 ( a e b) - Dados isotópicos ${ }^{207} \mathrm{~Pb} /{ }^{206} \mathrm{~Pb}$ em zircão dos granitóides do nordeste do Pará.

\begin{tabular}{|c|c|c|c|c|c|c|}
\hline Zircão & Temp. ${ }^{\circ} \mathrm{C}$ & Razões $^{2}$ & ${ }^{204} \mathrm{~Pb} /{ }^{206} \mathrm{~Pb} \pm 2 \sigma$ & $\begin{array}{c}{ }^{208} \mathrm{~Pb} /{ }^{206} \mathrm{~Pb} \\
\pm 2 \sigma \\
\end{array}$ & ${ }^{207} \mathrm{~Pb} /{ }^{206} \mathrm{~Pb} \pm 2 \sigma^{3}$ & $\begin{array}{l}\text { Idade } \\
(\mathrm{Ma})\end{array}$ \\
\hline \multicolumn{7}{|c|}{ Granito Tracuateua } \\
\hline $\mathrm{TZ} / 06$ & 1470 & 88 & $0,000045 \pm 3$ & $0,01502 \pm 7$ & $0,12875 \pm 19$ & $2.081 \pm 3$ \\
\hline \multirow[t]{2}{*}{$\mathrm{TZ} / 10$} & 1470 & 90 & $0,000127 \pm 9$ & $0,02909 \pm 22$ & $0,12873 \pm 31$ & $2.081 \pm 4$ \\
\hline & 1500 & 78 & $0,000009 \pm 5$ & $0,02035 \pm 50$ & $0,12918 \pm 51$ & $2.087 \pm 7$ \\
\hline $\mathrm{TZ} / 23$ & 1450 & 18 & $0,000276 \pm 20$ & $0,06601 \pm 62$ & $0,12822 \pm 51$ & $2.074 \pm 7$ \\
\hline \multirow[t]{2}{*}{$\mathrm{TZ} / 26$} & 1500 & 68 & $0,000033 \pm 5$ & $0,06295 \pm 29$ & $0,12829 \pm 30$ & $2.075 \pm 4$ \\
\hline & & & & & & $2.080 \pm 2$ \\
\hline $\mathrm{TZ} / 11^{1}$ & & & & & & $2.107 \pm 3$ \\
\hline \multicolumn{7}{|c|}{ Granito Mirasselvas } \\
\hline $\mathrm{M} / 01$ & 1500 & 86 & $0,000039 \pm 3$ & $0,04069 \pm 402$ & $0,13006 \pm 36$ & $2.099 \pm 5$ \\
\hline $\mathrm{M} / 02$ & 1500 & 86 & $0,000004 \pm 4$ & $0,00785 \pm 9$ & $0,12905 \pm 21$ & $2.085 \pm 3$ \\
\hline $\mathrm{M} / 03$ & 1500 & 36 & $0,000003 \pm 4$ & $0,01794 \pm 470$ & $0,12955 \pm 76$ & $2.092 \pm 10$ \\
\hline $\mathrm{M} / 06$ & 1450 & 84 & $0,000067 \pm 7$ & $0,13114 \pm 62$ & $0,12934 \pm 30$ & $2.089 \pm 4$ \\
\hline $\mathrm{M} / 10$ & 1470 & 16 & $0,000000 \pm 0$ & $0,03805 \pm 61$ & $0,12911 \pm 88$ & $2.086 \pm 12$ \\
\hline $\mathrm{M} / 13$ & 1470 & 88 & $0,000004 \pm 4$ & $0,03587 \pm 40$ & $0,12999 \pm 29$ & $2.098 \pm 4$ \\
\hline \multirow[t]{2}{*}{$\mathrm{M} / 14$} & 1470 & 72 & $0,000037 \pm 14$ & $0,06919 \pm 46$ & $0,12912 \pm 68$ & $2.086 \pm 9$ \\
\hline & & & & & & $2.091 \pm 5$ \\
\hline
\end{tabular}

1- Zircão herdado; 2- Número de razões utilizadas para o cálculo da idade; 3- Razões corrigidas 
Tabela 2 - Continuação.

(Domínio Móvel)

\begin{tabular}{|c|c|c|c|c|c|c|}
\hline Zircão & Temp. ${ }^{\circ} \mathrm{C}$ & Razões $^{2}$ & ${ }^{204} \mathrm{~Pb} /{ }^{206} \mathrm{~Pb} \pm 2 \sigma$ & $\begin{array}{c}{ }^{208} \mathrm{~Pb} /{ }^{206} \mathrm{~Pb} \\
\pm 2 \sigma\end{array}$ & ${ }^{207} \mathrm{~Pb} /{ }^{206} \mathrm{~Pb} \pm 2 \sigma$ & $\begin{array}{l}\text { Idade } \\
(\mathrm{Ma})\end{array}$ \\
\hline \multicolumn{7}{|c|}{ Granito Cantão } \\
\hline $\mathrm{CZ} / 03$ & 1550 & 86 & $0,000047 \pm 35$ & $0,09654 \pm 56$ & $0,13308 \pm 63$ & $2.139 \pm 8$ \\
\hline \multirow[t]{3}{*}{$\mathrm{CZ} / 04$} & 1500 & 90 & $0,000232 \pm 11$ & $0,09627 \pm 82$ & $0,13475 \pm 32$ & $2.161 \pm 4$ \\
\hline & 1550 & 32 & $0,000153 \pm 28$ & $0,12243 \pm 54$ & $0,13555 \pm 74$ & $2.172 \pm 10$ \\
\hline & & & & & & $2163 \pm 4$ \\
\hline \multicolumn{7}{|c|}{ Granitóide Japiim } \\
\hline $\mathrm{JP} / 01$ & 1550 & 16 & $0,000053 \pm 26$ & $0,10772 \pm 78$ & $0,12873 \pm 237$ & $2.081 \pm 32$ \\
\hline $\mathrm{JP} / 02$ & 1550 & 16 & $0,000070 \pm 32$ & $0,16170 \pm 146$ & $0,12924 \pm 178$ & $2.088 \pm 24$ \\
\hline $\mathrm{JP} / 03$ & 1500 & 86 & $0,000018 \pm 3$ & $0,11106 \pm 188$ & $0,12861 \pm 17$ & $2.079 \pm 2$ \\
\hline $\mathrm{JP} / 07$ & 1500 & 88 & $0,000030 \pm 3$ & $0,08339 \pm 40$ & $0,12915 \pm 20$ & $2.087 \pm 3$ \\
\hline \multirow[t]{2}{*}{$\mathrm{JP} / 08$} & 1500 & 86 & $0,000047 \pm 12$ & $0,11850 \pm 77$ & $0,12959 \pm 30$ & $2.093 \pm 4$ \\
\hline & & & & & & $2.084 \pm 5$ \\
\hline $\mathrm{JP} / 05^{1}$ & & & & & & $2.351 \pm 12$ \\
\hline \multicolumn{7}{|c|}{ Granitóide Jonasa } \\
\hline \multirow[t]{2}{*}{$\mathrm{Jo} / 05$} & 1550 & 90 & $0,000036 \pm 18$ & $0,02251 \pm 36$ & $0,12808 \pm 34$ & $2.072 \pm 5$ \\
\hline & 1600 & 52 & $0,000011 \pm 9$ & $0,01905 \pm 35$ & $0,12877 \pm 86$ & $2.081 \pm 12$ \\
\hline $\mathrm{Jo} / 10$ & 1500 & 88 & $0,000011 \pm 7$ & $0,11136 \pm 34$ & $0,12623 \pm 40$ & $2.046 \pm 6$ \\
\hline \multirow[t]{2}{*}{$\mathrm{Jo} / 14$} & 1580 & 86 & $0,000012 \pm 5$ & $0,00565 \pm 54$ & $0,12801 \pm 29$ & $2.072 \pm 4$ \\
\hline & & & & & & $2.072 \pm 3$ \\
\hline $\mathrm{Jo} / 03^{1}$ & & & & & & $2.325 \pm 10$ \\
\hline $\mathrm{Jo} / 04^{1}$ & & & & & & $2.374 \pm 6$ \\
\hline $\mathrm{Jo} / 07^{1}$ & & & & & & $2.387 \pm 5$ \\
\hline $\mathrm{Jo} / 08^{1}$ & & & & & & $2.446 \pm 7$ \\
\hline \multicolumn{7}{|c|}{ Granito Ney Peixoto } \\
\hline \multirow[t]{2}{*}{$\mathrm{NP} / 01$} & 450 & 90 & 0,0000118 & $0,07061 \pm 56$ & $0,05894 \pm 23$ & $565 \pm 8$ \\
\hline & 470 & 68 & $0,000000 \pm 0$ & $0,08524 \pm 64$ & $0,05870 \pm 14$ & $556 \pm 5$ \\
\hline \multirow[t]{2}{*}{$\mathrm{NP} / 05$} & 450 & 34 & $0,000000 \pm 0$ & $0,04755 \pm 344$ & $0,05835 \pm 34$ & $543 \pm 13$ \\
\hline & 470 & 66 & $0,000000 \pm 0$ & $0,51141 \pm 196$ & $0,05847 \pm 40$ & $548 \pm 15$ \\
\hline \multirow[t]{2}{*}{$\mathrm{NP} / 07$} & 500 & 70 & $0,000008 \pm 3$ & $0,04183 \pm 167$ & $0,05855 \pm 12$ & $551 \pm 4$ \\
\hline & 550 & 88 & $0,000084 \pm 14$ & $0,26501 \pm 155$ & $0,05811 \pm 36$ & $534 \pm 14$ \\
\hline \multirow[t]{2}{*}{$\mathrm{NP} / 10$} & 450 & 86 & $0,000021 \pm 1$ & $0,15964 \pm 861$ & $0,05831 \pm 12$ & $542 \pm 4$ \\
\hline & 500 & 18 & $0,000035 \pm 20$ & $0,10928 \pm 89$ & $0,05887 \pm 44$ & $563 \pm 16$ \\
\hline $\mathrm{NP} / 11$ & 500 & 76 & $0,000045 \pm 8$ & $0,10998 \pm 1269$ & $0,05837 \pm 12$ & $544 \pm 5$ \\
\hline \multirow[t]{3}{*}{$\mathrm{NP} / 15$} & 500 & 88 & $0,000014 \pm 2$ & $0,08050 \pm 65$ & $0,05845 \pm 13$ & $547 \pm 5$ \\
\hline & 550 & 72 & $0,000056 \pm 10$ & $0,22480 \pm 66$ & $0,05873 \pm 23$ & $557 \pm 8$ \\
\hline & & & & & & $549 \pm 4$ \\
\hline $\mathrm{NP} / 06^{1}$ & & & & & & $1.901 \pm 7$ \\
\hline
\end{tabular}

1- Zircão herdado; 2- Número de razões utilizadas para o cálculo da idade; 3- Razões corrigidas

piramidais, alongados segundo a orientação do seu eixo $\mathrm{C}$, tendo alguns as extremidades arredondadas. São translúcidos, incolores e com colorações castanho claro e róseo. Exibem inclusões, sobrecrescimento e borda metamítica. Dos 16 cristais analisados, sete forneceram sinal de $\mathrm{Pb}$ suficiente para análise isotópica. As idades ${ }^{207} \mathrm{~Pb} /{ }^{206} \mathrm{~Pb}$ variaram entre $2.085 \pm 3 \mathrm{Ma}$ e $2.099 \pm 5 \mathrm{Ma}$, definindo a idade média de $2.091 \pm 5 \mathrm{Ma}$ (Tab. 2).

O GC forneceu uma quantidade reduzida de zircões, em grande parte, metamitizados. Os seus cristais de zircão apresentam hábitos prismáticos, arredondados nas extremidades, sendo que alguns possuem faces bipiramidais bem definidas. São translúcidos, ou com colorações amarelada e castanho claro. Dos 11 cristais 
selecionados, apenas dois deles forneceram sinal de $\mathrm{Pb}$ suficiente para análise isotópica. $\mathrm{O}$ zircão $\mathrm{CZ} / 03$ forneceu a idade de $2.139 \pm 4 \mathrm{Ma}$ e o CZ/04 forneceu duas idades $(2.161 \pm 4$ e $2172 \pm 10 \mathrm{Ma})$ que definiram uma idade ${ }^{207} \mathrm{~Pb} /{ }^{206} \mathrm{~Pb}$ média de $2.163 \pm 4 \mathrm{Ma}$ (Tab. 2).

A amostra do GJp foi a que menos proporcionou zircão. Os cristais de zircão do GJp apresentam formas prismáticas, bipiramidais, alguns ovalados. São translúcidos, incolores, ou com colorações amarelada e castanho claro. Possuem inclusões, fraturas e raramente são metamíticos. Foram analisados nove cristais de zircão sendo que cinco cristais, variando entre $2.079 \pm 2$ Ma e $2.093 \pm 4 \mathrm{Ma}$, definiram uma idade de $2.084 \pm 5 \mathrm{Ma}$ (Tab. 2). Um zircão forneceu idade de $2.351 \pm 12 \mathrm{Ma}$ que foi interpretado como cristal herdado.

Os hábitos dos cristais de zircão do GJo são prismáticos, bipiramidais, ovalados e irregulares. Os cristais variam de translúcidos a incolores ou com coloração amarelada e castanho claro. Alguns contêm fraturas, inclusões e bordas metamíticas. Foram analisados 22 cristais de zircão sendo que 2 deles definiram uma idade média de $2.072 \pm 3 \mathrm{Ma}$ (Tab. 2). Vários cristais ofereceram idades mais antigas: $2.325 \pm 10(\mathrm{Jo} / 03)$, $2.374 \pm 6(\mathrm{Jo} / 04), 2.387 \pm 5(\mathrm{Jo} / 07)$ e $2.446 \pm 7 \mathrm{Ma}(\mathrm{Jo} / 08)$, sendo considerados zircões herdados.

O GNP forneceu diversos zircões prismáticos, bipiramidais, incolores e contendo raras inclusões. Doze cristais foram analisados e sete forneceram idades, variando entre $530 \pm 69 \mathrm{Ma}$ e $569 \pm 16 \mathrm{Ma}$, definindo uma idade média de $549 \pm 4 \mathrm{Ma}$ (Tab. 2). Um zircão con- siderado herdado forneceu idade de $1.901 \pm 7$ (NP/6).

Sm-Nd EM ROCHA TOTAL Os granitóides da área cratônica (GT e GM) têm $\varepsilon \mathrm{Nd}(\mathrm{t})$ aproximadamente entre $-1,3$ e 1,15 e idade $T_{D M}$, no intervalo de 2,31-2,50 $\mathrm{Ga}$ (Tab. 3). O mais antigo $(2,09 \mathrm{Ga})$ é relativamente mais positivo $(\varepsilon N d(t)=0,97$ e 1,15$)$ e tem $\mathrm{T}_{\text {DM }}$ próximo de $2,3 \mathrm{Ga}$. O GT (2,08 Ga), mais novo, possui valores de $\varepsilon N d(t)$ positivo e negativo $(0,12$ e $-1,33)$ e $T_{D M}$ $(2,46-2,50 \mathrm{Ga})$ mais antigas do que o GM.

Os GC, GJp e GJo que ocorrem no Cinturão de Cisalhamento Gurupi possuem valores de $\varepsilon \mathrm{Nd}(\mathrm{t})$ tanto negativos como positivos entre $-3,4$ e 3,2 e idades $T_{D M}$, no intervalo de aproximadamente 2,1-3,2 Ga (Tab. 3). Os três granitóides, de mesmo eon evolutivo, têm idades mínimas e $\mathrm{T}_{\mathrm{DM}}$ distintas. O GC $(2,16 \mathrm{Ga})$, o mais antigo de todos, tem $\varepsilon N d(t)$ de $-0,93$ e $2,68, T_{D M}$ entre 2,48 $2,21 \mathrm{Ga}$. O GJp (2,08 Ga) possui $\varepsilon \mathrm{Nd}(\mathrm{t}) \mathrm{de}-3,43$ e 1,89 , $\mathrm{T}_{\mathrm{DM}}$ entre 2,2-3,2 Ga. O mais novo granitóide de 2,07 Ga (GJo) tem $\varepsilon N d(t) d e-1,03$ e $3,25, T_{D M}$ entre 2,09 -2,4 Ga. O GNP, também situado no cinturão, de idade eocambriana $(550 \mathrm{Ma})$, possui $\varepsilon \mathrm{Nd}(\mathrm{t})$ fortemente negativo $\left(8,50\right.$ a 7,38) e $\mathrm{T}_{\mathrm{DM}}$ entre $1,60-1,78 \mathrm{Ga}$ (Tab. 3). A figura 2 destaca o modelo de evolução isotópica de $\mathrm{Nd}$ (De Paolo 1988) dos granitóides do nordeste do Pará.

DISCUSSÃO DOS RESULTADOS As idades mínimas de cristalização obtidas para os granitóides GJo e GJp, respectivamente, de 2.072 e $2.084 \mathrm{Ma}$, remetem a geração destes corpos ao Paleoproterozóico. Portanto,

Tabela 3 - Dados Sm/Nd em rocha total dos granitóides do nordeste do Estado do Pará.

\begin{tabular}{|c|c|c|c|c|c|c|c|c|c|}
\hline Amostras & Idade (Ga) & $\begin{array}{c}\mathrm{Sm} \\
(\mathrm{ppm})\end{array}$ & $\begin{array}{c}\mathrm{Nd} \\
(\mathrm{ppm})\end{array}$ & $\mathrm{Sm} / \mathrm{Nd}$ & ${ }^{147} \mathrm{Sm} /{ }^{144} \mathrm{Nd}$ & ${ }^{143} \mathrm{Nd} /{ }^{144} \mathrm{Nd}$ & $\begin{array}{c}\varepsilon N d \\
(0)\end{array}$ & $\begin{array}{c}\varepsilon^{\varepsilon N d} \\
(\mathrm{t})\end{array}$ & $\begin{array}{l}\text { TDM } \\
(\mathrm{Ga}) \\
\end{array}$ \\
\hline \multicolumn{10}{|l|}{ Cráton São Luís } \\
\hline Granito Mirasselvas & 2,09 & & & & & & & & \\
\hline M-2B & & 3,93 & 18,56 & 0,212 & 0,12808 & 0,511743 & $-17,46$ & 0,97 & 2,32 \\
\hline $\mathrm{M}-2 \mathrm{C}$ & & 3,96 & 18,33 & 0,216 & 0,13054 & 0,511786 & $-16,62$ & 1,15 & 2,31 \\
\hline Granito Tracuateua & 2,08 & & & & & & & & \\
\hline $\mathrm{T}-01$ & & 1,79 & 7,54 & 0,237 & 0,14324 & 0,511912 & $-14,16$ & 0,19 & 2,46 \\
\hline $\mathrm{T}-03$ & & 3,58 & 18,13 & 0,197 & 0,11938 & 0,511506 & $-22,08$ & $-1,33$ & 2,50 \\
\hline \multicolumn{10}{|l|}{ Cinturão Gurupi } \\
\hline Granito Cantão & 2,16 & & & & & & & & \\
\hline C-01 & & 4,34 & 25,11 & 0,173 & 0,10452 & 0,511279 & $-26,51$ & $-0,93$ & 2,48 \\
\hline C-02 & & 4,49 & 26,13 & 0,172 & 0,10387 & 0,511454 & $-23,10$ & 2,68 & 2,21 \\
\hline Granitóide Japiim & 2,08 & & & & & & & & \\
\hline $\mathrm{J}-02$ & 2,08 & 5,66 & 27,32 & 0,207 & 0,12534 & 0,511757 & $-17,19$ & 1,89 & 2,22 \\
\hline $\mathrm{J}-03$ & 2,08 & 3,69 & 13,67 & 0,270 & 0,16327 & 0,512005 & $-12,35$ & $-3,43$ & 3,23 \\
\hline Granitóide Jonasa & 2,07 & & & & & & & & \\
\hline TAG-02 & & 2,37 & 13,96 & 0,170 & 0,10269 & 0,511304 & $-26,02$ & $-1,03$ & 2,40 \\
\hline TAG-05 & & 2,89 & 13,50 & 0,214 & 0,12928 & 0,511885 & $-14,69$ & 3,25 & 2,09 \\
\hline Granito Ney Peixoto & 0,55 & & & & & & & & \\
\hline NP-01 & & 4,82 & 24,83 & 0,194 & 0,11741 & 0,511917 & $-14,06$ & $-8,50$ & 1,78 \\
\hline NP-02 & & 3,59 & 19,86 & 0,181 & 0,10926 & 0,511945 & $-13,52$ & $-7,38$ & 1,60 \\
\hline
\end{tabular}




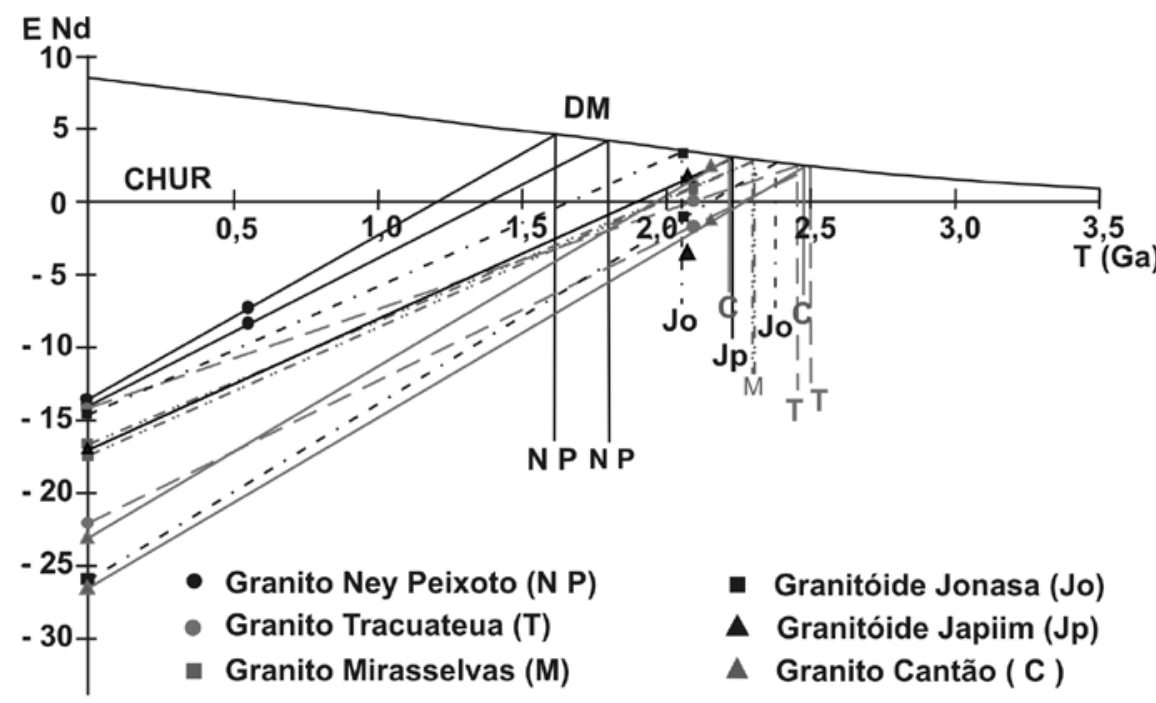

Figura 2 - Diagramas $\varepsilon N d$ versus tempo geológico. Modelo de evolução isotópica de Nd (De Paolo 1988) dos granitóides do nordeste do Pará.

não mais se sustenta à inserção destes corpos na Suíte Brasiliana, como indicado por Costa (2000). A melhor proposição seria na Suíte Tracuateua. As datações $(\mathrm{Rb} /$ $\mathrm{Sr}$ e K/Ar) anteriores, que atribuíram idade paleoproterozóica (Tab. 1a) aos granitóides GT, GM e GC foram ratificadas pelas idades mínimas de $2.080,2.091 \mathrm{e}$ $2.163 \mathrm{Ma}$, respectivamente, apresentadas neste trabalho. $\mathrm{O}$ zircão de $2.107 \mathrm{Ma}$ encontrado no GT indica a possibilidade da ocorrência de um núcleo herdado, de uma crosta mais antiga, o que é reforçado pelas sua idade $\mathrm{T}_{\mathrm{DM}}$, em torno de 2,5 Ga. A idade apresentada por Oliveira (1997) de 2.400 Ma para o GJo e a idade de um zircão herdado $(\mathrm{Jo} / 8=2.446 \pm 7 \mathrm{Ma})$, obtida neste trabalho para o mesmo corpo, sugerem a existência de uma crosta formada no início do Paleoproterozóico. Esta hipótese é reforçada pela idade $\mathrm{T}_{\mathrm{DM}}$ de $2,40 \mathrm{Ga}$ calculada para esse granitóide. Outros zircões herdados foram encontrados no GJo e GJp. Os cristais com idades entre 2.325-2.387 (Tab. 2) sugerem a existência, na região, de crosta formada ao redor de 2,35 Ga. Esta idéia se fortalece quando se consideram os resultados das idades $\mathrm{T}_{\mathrm{DM}}$ dos corpos paleoproterozóicos situadas, na maioria, entre 2,2 - 2,4 Ga. Esse quadro é análogo ao do Cráton Oeste Africano nas relações entre os granitóides e as seqüências supracrustais Birrimianas, claramente registradas e atribuídas à atuação de dois eventos principais: Burquiniano $(2,4$ $-2,15 \mathrm{Ga})$ e Eburneano (2,15-1,95 Ga). Os valores de $\varepsilon \mathrm{Nd}(\mathrm{t})$ revelam que os granitóides paleoproterozóicos (GT, GM, GJp, GJo e GC), em relação à fonte, encerrariam importante mistura de fontes crustal e mantélica.

EVOLUÇAO TECTÔNICA Com base nos dados geocronológicos anteriores e naqueles apresentados neste trabalho, configura-se na região do Gurupi, duas granitogênese principais, as quais podem ser correlacionadas, como no caso africano, a dois eventos geotectônicos distintos. A primeira, situada entre 2,15-2,16 Ga, teria gerado os granitóides da Suíte Tromaí (plútons do tipo I), podendo ser também aí inserido o GC, de idade $2,16 \mathrm{Ga}$ em novo evento tectonotermal, ora denominado Evento Gurupiense, com intervalo temporal semelhante ao Burquiniano. A segunda, mais nova, com idade entre 2,07-2,09 Ga, seria responsável pela formação dos corpos granitóides, do tipo S, da Suíte Tracuateua, correlacionada ao Evento Transamazônico. A associação desses granitóides, de naturezas distintas com seqüências supracrustais, envolvendo rochas de derivação ígnea e sedimentar, deformadas e metamorfisadas, indicam um ambiente geotectônico de interações colisionais entre arcos de ilhas e bacias vulcanossedimentares, com núcleos arqueanos. Este quadro é largamente descrito no Cráton Oeste Africano, o qual, no caso da região do Gurupi, aconteceu durante o Evento Transamazônico.

Foi ratificada pela idade de $550 \mathrm{Ma}$, obtida neste trabalho, a datação Rb-Sr, em rocha total do GNP, a última manifestação magmática nessa região, no Eocambriano, durante o Evento Brasiliano (Tab. 1b). As idades $\mathrm{T}_{\mathrm{DM}}$ ao redor de 2,0 Ga e $\varepsilon \mathrm{Nd}(\mathrm{t})$ fortemente negativos evidenciam uma derivação a partir do retrabalhamento de crosta continental paleoproterozóica. Essa suposição é validada pela presença de zircão herdado de 1,9 Ga. Como representa, petrograficamente, um granito a duas micas, também pode ser sugerido uma origem ligada a fusões localizadas, a partir de imbricações de crosta paleoproterozóica (Grupo Gurupi e granitóides). Não se descarta a possibilidade de contribuição da Alcalina Boca Nova (Tab. 1b), como também dos corpos graníticos tardios (sienitos e granitos), que são encontrados no Cráton Oeste Africano (1.800-1.500 Ma) (Trompette 1994).

Considerando que todos os granitóides descritos, a exceção do GNP, são de idade paleoproterozóica, a crosta exposta por toda a região é basicamente de idade paleoproterozóica. Assim, a granitogênese relacionada ao Brasiliano é ainda mais restrita na região, do que an- 
teriormente considerada e podem ser caracterizados, de forma principal, pelo retrabalhamento de rochas já existentes, com a formação de estruturas planares e lineares, sob condição dúctil-rúptil. Por essa razão as idades K-Ar, e mesmo algumas $\mathrm{Rb}-\mathrm{Sr}$ obtidas nas proximidades da Zona de Cisalhamento Tentugal e daí para sudoeste, têm mostrado resultados geocronológicos compatíveis com a atuação desse evento, por serem esses geocronômetros mais sensíveis aos efeitos tectonotermais.

O retrabalhamento da borda cratônica, na qual se assinala a colocação de rochas alcalinas, a concentração de deformação a partir da Zona de Cisalhamento Tentugal, da qual resultaram foliações e lineações e mais tardiamente falhas e juntas, a cinemática estabelecida sobre essa porção crustal que gerou uma grande movimentação de massas rochosas resultaram na implantação do Cinturão de Cisalhamento Gurupi, em cuja evolução se distingue dois estágios: colisão oblíqua e transcorrência sinistral (Pastana 1995, Borges et al. 1996, Costa \& Hasui 1997, Costa 2000).

CONCLUSÕES Os estudos dos granitóides da região do Gurupi permitem as seguintes contribuições ao conhecimento geológico regional:

A história evolutiva desse segmento crustal é complexa. Envolve a participação de terrenos arqueanos, revelados a partir de dados indiretos ainda esparsos, mas consistentes e um quadro paleoproterozóico, configurado pela associação de fenômenos geológicos distintos que aconteceram em intervalos temporais bem definidos. Isso é sustentado pelas idades $\mathrm{T}_{\mathrm{DM}}$ de $2,50 \mathrm{Ga}$ e 3,23 Ga, encontradas, respectivamente, nos granitóides Tracuateua e Japiim; e valores de $\varepsilon N d$ negativos de $-0,93 \mathrm{a}-3,43$, indicativos de fontes geradoras, a partir de materiais crustais arqueanos;

Idades de zircões herdados, encontrados nos corpos Jonasa e Japiim, com certa freqüência de valores entre 2,44 e 2,32 e idades $\mathrm{T}_{\mathrm{DM}}$ entre 2,2 - 2,4 indicam uma correlação entre processos geológicos locais com aqueles descritos no Cráton Oeste Africano, durante o Evento Burquiniano. Isso sugere a existência de um evento tectonotermal, inclusive com granitogênese, ainda não descrito na literatura geológica da região para o qual propomos a denominação Evento Gurupiense $(2.4-2.15 \mathrm{Ga})$;

Os granitóides estudados podem ser classificados da seguinte forma: (i) com relação à idade: Granito Cantão de 2,16 Ga, correlacionado aos granitóides tipo I da Suíte Tromaí (2,15 Ga); 2,07-2,09 Ga - granitóides tipo S da Suíte Tracauteua (Tracuateua, e Mirasselvas), incluindo Jonasa e Japiim; (ii) com relação à fonte : a Suíte Tracuateua representa mistura de fontes mantélica e crustal, assim como o Granito Cantão.

Os resultados $\mathrm{Sm} / \mathrm{Nd}$ sugerem para os magmas genitores dos granitóides paleoproterozóicos contribuição crustal do início do Paleoproterozóico (maior contribuição) e do Arqueano (menor contribuição) ( $\varepsilon \mathrm{Nd}$ entre $-0,93--3,43)$. As idades $\mathrm{T}_{\mathrm{DM}}$ calculadas entre 2,3-2,40 Ga e 2,5-3,23 Ga não são indicações da diferenciação dos protólitos do manto, por se tratar de mistura de fontes.

O magmatismo brasiliano, na região nordeste do Pará, constitui-se uma manifestação restrita e tem como representante o Granito Ney Peixoto (550 Ma). Seu protólito tem idade paleoproterozóica ( $\mathrm{T}_{\mathrm{DM}}=1,6-1,8 \mathrm{Ga}$, zircão herdado de $1,9 \mathrm{Ga})$ e a sua fonte é crustal $(-8,5--7,38)$.

A partir da Zona de Cisalhamento Tentugal, em direção a sudoeste, no que se denomina Cinturão de Cisalhamento Gurupi, as rochas ocorrentes, que são continuidades daquelas que compõem o Cráton São Luís, encontram-se estruturalmente na direção NW-SE, ou seja, o Cráton tem a sua borda retrabalhada, sob condições físicas que se situam no domínio deformacional dúctil-rúptil.

Agradecimentos Os autores agradecem ao Laboratório de Geologia Isotópica (Pará-Iso)/UFPA pela realização das datações, ao PRONEX - Projeto Magmatismo, metalogênese e evolução crustal da Província Carajás e província adjacentes, ao CNPq que concedeu bolsa de pesquisa (mestrado) ao primeiro autor, as geólogas Adriana Saraiva, Cristiane Souza, Érica Viana, Luciene Leão e Roberta Tavares pela preparação das amostras para datação $\mathrm{Pb}-\mathrm{Pb}$ e aos revisores anônimos pelas sugestões ao manuscrito.

\section{Referências}

Abreu F.A.M. 1990. Evolução geotectônica do PréCambriano na região meio norte do Brasil $e$ sua correlação com a África Ocidental. Tese de Doutoramento, Centro de Geociências, Universidade Federal do Pará, 440 p.

Abreu F.A M. \& Lesquer A. 1985. Considerações sobre o Pré-Cambriano da região Sul-Sudoeste do Cráton São Luís. In: SBG, Simp. de Geol. Amazônia, 2, Atas, p. 7-21.

Almeida H.G.G. 2000. Programa Grande Carajás - São Luís; Folha SA.23 Escala 1: 1.000.000. Estados do Pará e Maranhão (Programa de Levantamentos Básicos do Brasil). Brasília, CPRM. CD-Rom.

Almeida F.F.M., Melcher G.C., Cordani U.G., Kawashita K.,
Vandoros P. 1968. Radiometric age determinations from northern Brazil. Bol. Soc. Bras. Geol., 7(1):3-14.

Borges M.S., Angélica R.S., Costa M.L. 1988. Contribuição a geologia da região de Santa Luzia do Pará, nordeste do Pará. In: SBG, Cong. Bras. Geol., 35, Anais, 6:26892703.

Borges M.S., Costa J.B.S., Bemerguy R.L., Costa J.L., Maia R.G.N., Araújo O.J.B. 1996. O quadro lito-estrutural da Folha SA-23-V-C (Castanhal). In: SBG, Cong. Bras. de Geol., 38, Anais, p. 113-114.

Cordani U.G., Brito Neves B.B., Fuck R.A., Porto R., Thomaz Filho A., Cunha F.M.B. 1984. Evolução preliminar de integração do Pré-Cambriano com os eventos tectônicos das bacias sedimentares brasileiras. 
Rio de Janeiro, PETROBRAS. Série Ciências-TécnicasPetróleo, Seção: Exploração de Petróleo 15, 70 p.

Costa J.B.S. \& Hasui Y. 1997. O Pré-Cambriano da região Amazônica no Brasil. In: Simp. Nacional de Estudos Tectônicos, 6, Bol. Exp., p. 39-41.

Costa J.B.S., Pastana J.M.N., Costa E.J.S., Jorge João X.S. 1988. A Faixa de Cisalhamento Tentugal na Folha SA 23-Y-B. In: SBG, Cong. Bras. de Geol., 35, Anais, 5, p. 2257-2266.

Costa J.L. 2000. Folha Castanhal (SA-23-V-C). estado do Pará, escala 1:250.000 (Programa de Levantamentos Geológicos Básicos do Brasil/Programa Grande Carajás). Brasília, CPRM, CD-Rom.

De Paollo D.J. 1988. Neodymium isotope geochemistry: an introduction. New York, Springer-Verlag, $187 \mathrm{p}$.

Gorayeb P.S.S., Gaudette H.G., Moura C.A.V., Abreu F.M. 1999. Geologia e geocronologia da Suíte Rosário, nordeste do Brasil e sua contextualização geotectônica. Rev. Bras. Geoc., 29(4):571-578.

Hurley P.M., Almeida F.F.M., Melcher G.C., Cordani V.G., Rand J.R., Kawashita K., Vandoros P., Pinson W.H., Fairbairn H.W. 1967. Test of drift by comparision of radiometric ages. Science, 157:495-500.

Klein E.L. 1998. Aspectos geoquímicos, geocronológicos e estudos dos fluidos associados às mineralizações auríferas do garimpo Caxias e Areal, Cráton São Luís, noroeste do Maranhão. Dissertação de Mestrado, Universidade Federal do Rio Grande do Sul, 189p.

Klein E.L. \& Moura C.A.V. 2001. Age constraints on granitoids and metavolcanic rocks of the São Luís Craton and Gurupi Belt, northern Brazil: implications for lithostratigraphy and geological evolution. International Geology Review, 43:237-253.

Kober B. 1986. Whole grain evaporation for ${ }^{207} \mathrm{~Pb} /{ }^{206} \mathrm{~Pb}$ age investigations on single zircons using a double filament source. Contrib. Mineral. Petrol., 93:482-490.

Kober B. 1987. Single grain evaporation combined with $\mathrm{Pb}^{+}$emitter bedding for ${ }^{207} \mathrm{~Pb} /{ }^{206} \mathrm{~Pb}$ investigations using thermal ion mass spectrometry and implications for zirconology. Contrib. Mineral. Petrol., 96:63-71.

Lowell G. R. 1985. Petrology of the Bragança batholith São Luís Cráton. In: Board W.L. \& Li-Jen W.U. (eds.) The crust-the significance of granites-gneisses on the lithosphere. Athens, Theophrautus Publications S.A., p. 13-34.

Palheta E.S.M. 2001. Evolução geológica da região nordeste do estado do Pará com base em estudos estruturais e isotópicos de granitóides. Dissertação de Mestrado, Centro de Geociências, Universidade Federal do Pará, $144 \mathrm{p}$.

Pastana J.M.N. 1995. Folhas Turiaçu (SA 23-V-D) e Pinheiro (SA 23-Y-B), estados do Pará e Maranhão, escala 1:250.000. (Programa de Levantamentos Geológicos Básicos/Programa Grande Carajás). Brasília, CPRM, $240 \mathrm{p}$.

Trompette R. 1994. Geology of western Gondwana (2000 - 500 Ma): Pan-african/Brasiliano aggregation of South America and África. Rotterdan, A.A. Bakelma Publishers, $350 \mathrm{p}$.

Villas R.N.N. 1982. Geocronologia de intrusões ígneas na bacia do rio Guamá, nordeste do estado do Pará. In: SBG, Simp. Geol. Amazônia, 1. Atas, 1:233-247.

Wanderley Filho J. R. 1980. Geologia do Granitóide Mirasselvas, nordeste do Pará. In: SBG, Cong. Bras. Geol., 31, Resumos, 2:426.

Manuscrito ID12670

Submetido em 23 de outubro de 2008 Aceito em 05 de novembro de 2009 